\title{
Melanoma and pigmentation of the leptomeninges in Ugandan Africans
}

\author{
M. G. LEWIS \\ From the Pathology Department, Makerere Medical College, Kampala, Uganda
}

SYNOPSIS A case of leptomeningeal melanoma in an African child of 7 years is presented together with a survey of pigmentation in the normal African brain.

There is a direct relationship between the depth of pigment of the leptomeninges and the skin in Ugandan Africans, suggesting that similar factors operate in the control of melanocytes in these two sites.

One of the earliest recorded cases of melanoma of the leptomeninges was described in 1861 by Rokitansky and these tumours have been the source of considerable interest and controversy over the years. Single case reports have appeared in the literature, and these have been extensively reviewed by Gibson, Burrows, and Weir (1957). They collected a total of 66 cases of meningeal melanosis, both benign and malignant, from the world literature. Since this condition appears to be such a relative rarity, it was decided to present the findings of a child seen in Uganda, and to report a study of pigmentation of the leptomeninges and the relationship to skin pigment in Ugandan Africans.

\section{CASE HISTORY}

A 7-year-old female Muganda child was admitted with a four-week history of headaches and inability to walk or swallow. There was a history of a similar episode at the age of 3 from which she apparently recovered completely.

On examination the child was comatose, with slight neck rigidity and papilloedema. Lumbar puncture revealed normal cerebrospinal fluid.

The child did not regain consciousness and died.

\section{POST-MORTEM EXAMINATION}

The main abnormalities of interest were confined in the cranial cavity. The brain was oedematous and weighed $1,200 \mathrm{~g}$. The entire surface was covered with black pigment located in the leptomeninges with only small areas spared (Fig. 1). This pigmentation extended over the cerebellar hemispheres, the brainstem, and spinal cord. On cutting the meninges with scissors, thick black pigment, rather like indian ink, characteristic of melanin, was released.

Received for publication 20 June 1968.

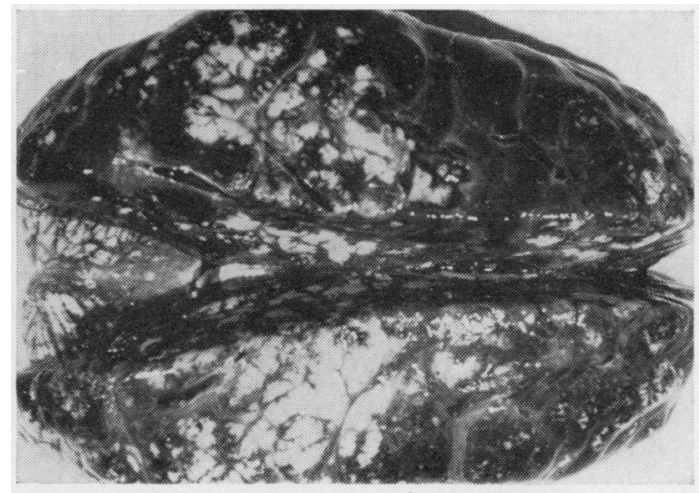

FIG. 1. Surface of brain covered with black pigment.

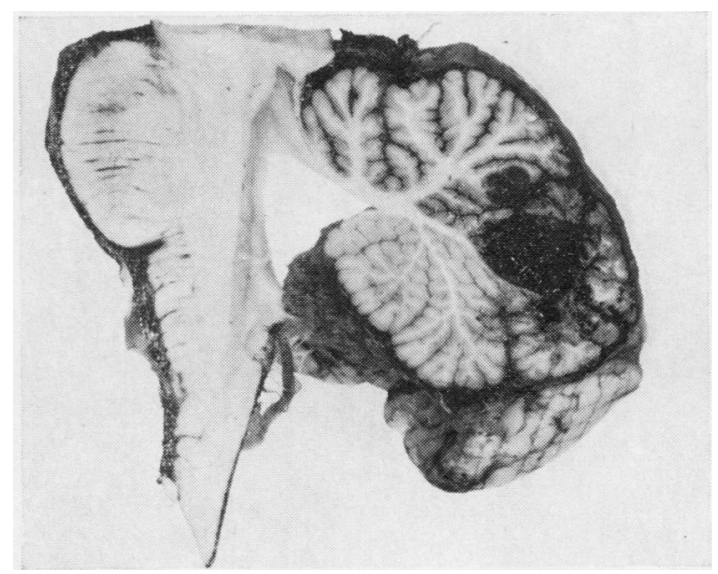

FIG. 2. Black tumour in anterior part of the cerebellum. Note the dilated fourth ventricle. 


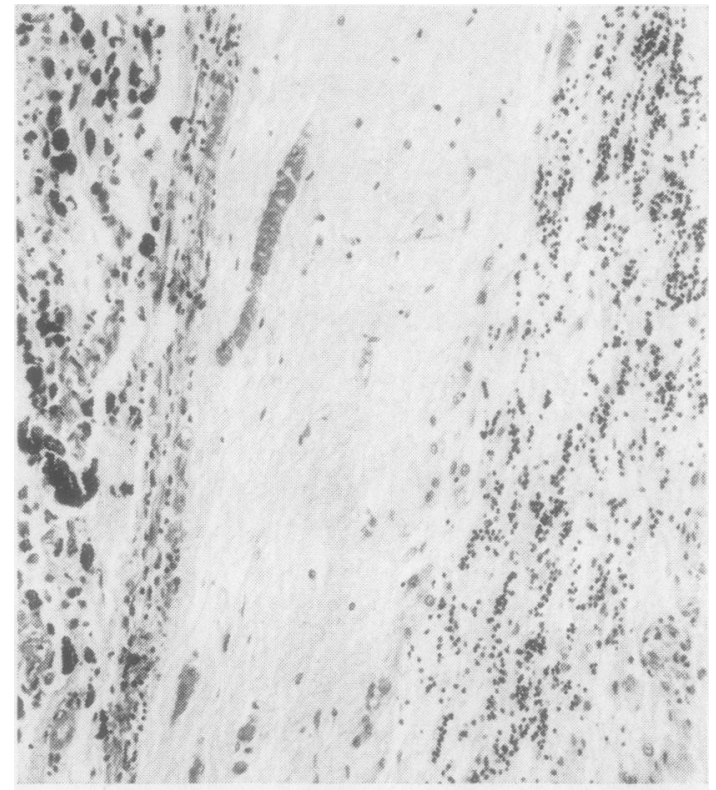

FIG. 3. Spindle-shaped heavily pigmented cells filling the subarachnoid spaces and extending into the Virchow-Robin spaces.

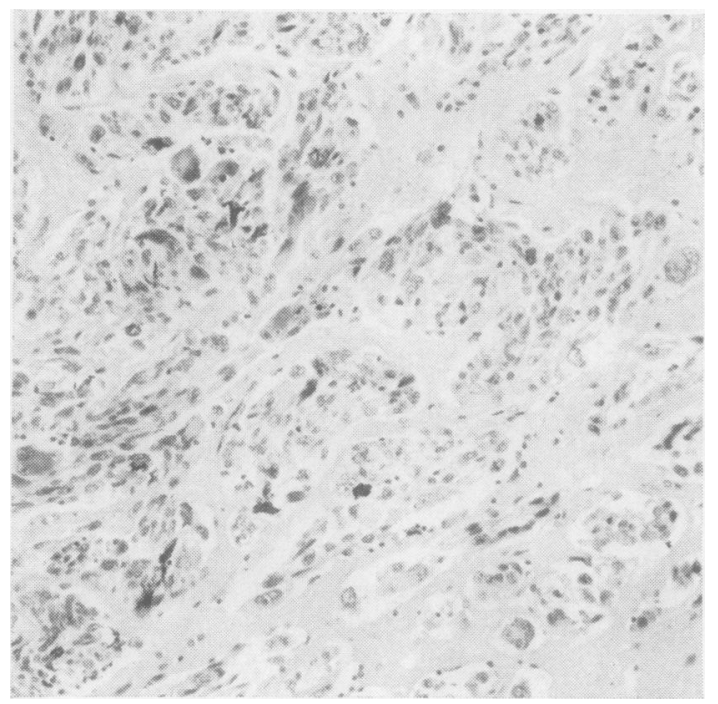

FIG. 4. Pleomorphic cells, many containing melanin, in a tumour of the cerebellum.

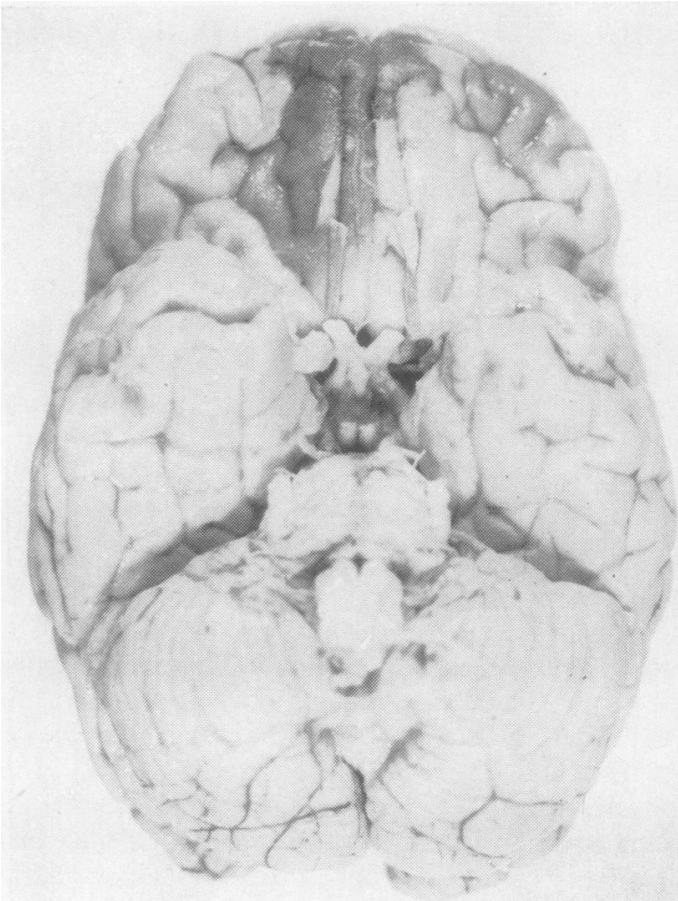

FIG. 5 .

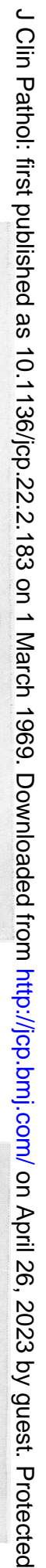

FIG. 6.

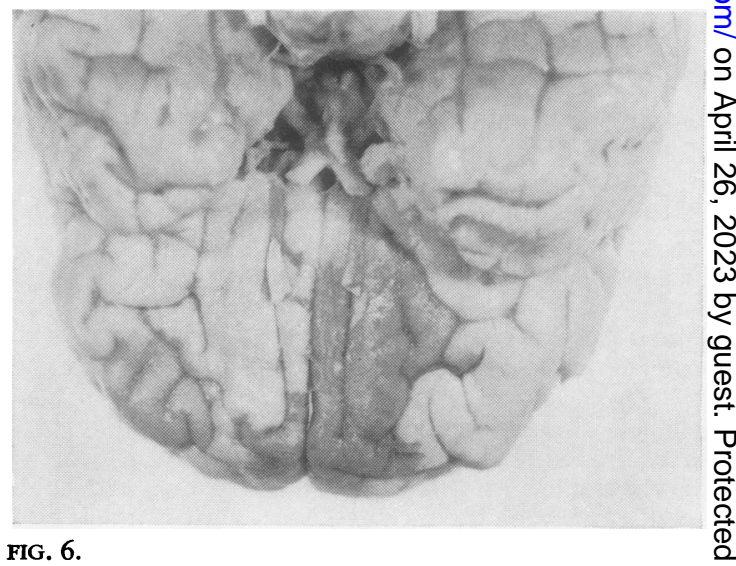

FIGS. 5 and 6. Pigmentation of the normal leptomeninges in an African. 
On cutting the brain, a single black tumour was seen in the cerebellum (Fig. 2) communicating with the surface pigmentation. In addition a well marked internal hydrocephalus was noted. No other abnormality was found and no other pigmented tumours of the central nervous system were discovered. A careful search was made for signs of other melanotic tumours in the body but none were found.

\section{MICROSCOPICAL EXAMINATION}

The subarachnoid spaces and Virchow-Robin spaces were tilied with spindle cell and pleomorphic cells laden with melanin (Fig. 3).

The cerebellar tumour was composed of similar cells, many containing melanin, arranged in clumps and sheets with evidence of invasion of adjacent tissues (Fig. 4).

\section{PIGMENTATION OF LEPTOMENINGES IN UGANDAN AFRICANS}

This study was prompted by the case of leptomeningeal melanoma described and by the controversies regarding the possible origins of the melanocyte in this region (Willis, 1960), and the object was to determine the normal distribution of visible pigment in the leptomeninges in Ugandan Africans and to determine if there was any recognizable relationship between this and skin pigmentation.

\section{METHODS AND MATERIALS}

A random selection of brains of all ages and tribes was examined in the postmortem room, and the areas of visible pigment were noted. The tribe, age, sex, and degrees of skin pigment were also recorded. The skin of each case was subjectively graded as light, medium or dark. The degree of involvement of the leptomeninges with visible pigment was graded as nil or very slight (brainstem only), moderate, with involvement of the brainstem and optic chiasma, and extensive, involving the brainstem, chiasma, and areas of the ventral and dorsal surface of the hemisphere (Figs. 5 and 6).

\section{RESULTS}

The results of these observations can be seen in the Table.

Although these figures are subjective, they show a definite trend: the light-skinned Africans have little or no pigment of the meninges while the very dark-skinned people show more widespread pigmentation. The relatively smaller numbers of darkskinned Africans is largely due to the fact that most of the patients seen in the postmortem room are derived from the tribes close to Kampala, who are Bantu and in general paler than the northern tribes
TABLE

LEPTOMENINGEAL PIGMENT AND SKIN PIGMENTATION IN UGANDAN AFRICANS

\begin{tabular}{|c|c|c|c|c|c|c|c|}
\hline \multirow{3}{*}{$\begin{array}{l}\text { Brain } \\
\text { Pigment }\end{array}$} & \multicolumn{7}{|c|}{ Skin Pigmentation } \\
\hline & \multicolumn{2}{|c|}{ Light } & \multicolumn{2}{|c|}{ Medium } & \multicolumn{2}{|c|}{ Dark } & \multirow[t]{2}{*}{ Total } \\
\hline & $O$ & $\boldsymbol{E}$ & $O$ & $\boldsymbol{E}$ & $O$ & $\boldsymbol{E}$ & \\
\hline \multirow[t]{2}{*}{$\begin{array}{l}\text { Scanty } \\
\text { Moderate } \\
\text { Extensive }\end{array}$} & $\begin{array}{r}14 \\
8 \\
1\end{array}$ & $\begin{array}{r}11 \cdot 72 \\
6 \cdot 08 \\
5 \cdot 21\end{array}$ & $\begin{array}{r}12 \\
5 \\
6\end{array}$ & $\begin{array}{r}11 \cdot 72 \\
6 \cdot 08 \\
5 \cdot 21\end{array}$ & $\begin{array}{l}1 \\
1 \\
5\end{array}$ & $\begin{array}{l}3.57 \\
1.85 \\
1.58\end{array}$ & $\begin{array}{l}27 \\
14 \\
12\end{array}$ \\
\hline & 23 & & 23 & & 7 & & $53 \mathrm{cas}$ \\
\hline
\end{tabular}

$O=$ Observed; $E=$ Expected.

$x^{2}=14.41$ (4 df) $P<0.01$

Comparison between scanty and moderate $x^{2}=0.44$ NS 2 df

Comparison between scanty + moderate and extensive $=$ $14.06,2$ df, $P<0.001$

of Hamitic or Sudanic origin. There appears to be a direct relationship between the depth and extent of pigmentation of the meninges and the skin.

\section{DISCUSSION}

Melanoma and melanosis of the leptomeninges have been reviewed by Gibson et al (1957) who found 66 cases in the world literature up to that time and classified them into two groups: (1) diffuse tumour of the meninges, especially at the base of the brain and around the spinal cord; (2) discrete foci of melanoma cells with diffuse meningeal distribution also present.

Discrete single tumours were the exception, and the main sites were frontal, parietal, and occipital lobes (nine authors), basal ganglia and cerebral peduncles (one author). Fowler and Simpson (1962) reported a malignant cerebellar tumour in a 21-year-old male Caucasian, which they interpreted as a medulloblastoma with neuroepithelium containing large amounts of melanin. Salm (1967) has recently reported a malignant melanoma of the cerebellum with extension into the meninges and a metastasis to the lungs in a 43-year-old Caucasian woman.

The present case shows well marked leptomeningeal melanosis and a malignant melanoma in the cerebellum. The age of the child and the absence of any other melanotic tumours makes this a reasonably convincing case. Regarding the histogenesis of primary malignant melanoma of the leptomeninges, it has been stated that the origin of the melanin-containing cells is uncertain (Willis, 1960).: The source of diffuse or local melanotic tumours in this site is certainly the elongated and branched pigment cells normally seen in the pia mater, especially in dark-skinned and Mongolian people (Willis, 1960). Willis (1965) considers that there may well be a common underlying anomaly of 
melanogenesis in both skin and leptomeninges. This does not, of course, imply that both are derived from the neural crest since melanocytes in both these sites could equally have been derived from a mesenchymal source. In support of this concept of a possible connexion between pigmentation of the skin and leptomeninges, several authors have quoted examples of pigmented skin naevi in association with leptomeningeal melanosis (Grahl, 1906; Schopper, 1913; Lua, 1914; MacLachlan, 1914; Berblinger, 1915; Hellmann, 1931 ; Bjorneboe, 1934; Lecoutourier, Ley, Titeca, and Van Bogaert, 1939; Touraine, 1949), showing that the neurocutaneous pigmentation was a familiar condition transmitted as a Mendelian dominant. Several such familial cases have been added since by Ketels-Harken (1963) and Tventson (1965).

The results show an association between the depth and extent of pigmentation in the normal meninges and the normal skin. This is unlikely to be true for Africans only, and the less easily recognized melanocyte in Caucasian leptomeninges must be the cell of origin of this rare condition of leptomeningeal melanosis and malignant melanoma.

I am grateful to Professor R. S. F. Schilling, of the London School of Hygiene and Tropical Medicine, for his advice and to Miss Walford who did the statistical test incorporated in the Table.

\section{REFERENCES}

Berblinger, W. (1915). Virchows Arch. path. Anat., 219, 328. Bjorneboe, M. (1934). Frankfurt Z. Path., 47, 363.

Fowler, M., and Simpson, D. A. (1962). J. Path. Bact., 84, 307.

Gibson, J. B., Burrows, D., and Weir, W. P. (1957). Ibid., 74, 419. Grahl, F. (1906). Beitr. path. Anat., 39, 66.

Hellmann, P. (1931). Zbl. Allg. Path. path. Anat., 52, 369.

Ketels-Harken, H. (1963). Ibid., 104, 396. Ketels-Harken, H. (1963). Ibid., 104, 396.
Lecoutourier, R., Ley, J., Titeca, J., and van Bogaert, L. (1939).
J. belge Neurol. Psychiat., 39, 103 .

Lua, M. (1914). Arch. Psychiat., 53, 895.

Maclachlan, W. G. (1914). J. med. Res., 24, 433

Rokitansky, S. (1861). Allg. wien. med. Ztg., 6, 113.

Salm, R. (1967). J. Path. Bact., 94, 196.

Schopper, K. S. (1913). Frankfurt. Z. Path., 13, 77.

Touraine, A. (1949). Ann. Derm. Syph. (Paris), 9, 489.

Tventson (1965). Acta path. microbiol. scand., 63, 1.

Willis, R. A. (1960). Pathology of Tumours, 3rd ed., p. 917. Butterworths London.

_ (1965). Med. J. Aust., 1, 827. 